\section{Air has never been easier}

DentalAir has made your air supply easier than ever before with its new service - 'Air to the Chair'.

By paying just $£ 5$ per week for every chair for which you need an air supply, you not only benefit from installation of a new air supply but also all of the associated maintenance, necessary certification and support. Your 'Air to the Chair' can be taken out in 36 month or 60 month contracts, but these can be adapted during this time to suit any changes needed - for example, if you require an air supply to more chairs.

So, what are you waiting for? Access the 'Air to the Chair' portal on the DentalAir website here: www.dentalair.com.

For more information, contact DentalAir at info@dentalair. com or call 08009757530 .

\section{Direct composites made to last}

Strength, beauty, value and endurance - this is what patients want from restorations. But what if they knew that this could be achieved in one visit?

COLTENE's BRILLIANT COMPONEER - prefabricated veneer shells - will enable dentists to offer exceptional restorations in a single appointment.

As for more benefits to you, dentists using BRILLIANT COMPONEER report how the material is easy to handle, the results are great, and it is a cost-effective choice too.

With the shells being so thin, optimal healthy tooth structure is preserved, making BRILLIANT COMPONEER a minimally invasive solution.

Contact COLTENE to find out how its materials could upgrade your restorations.

For more on COLTENE, visit www.coltene.com, email info. uk@coltene.com or call 08002545115.

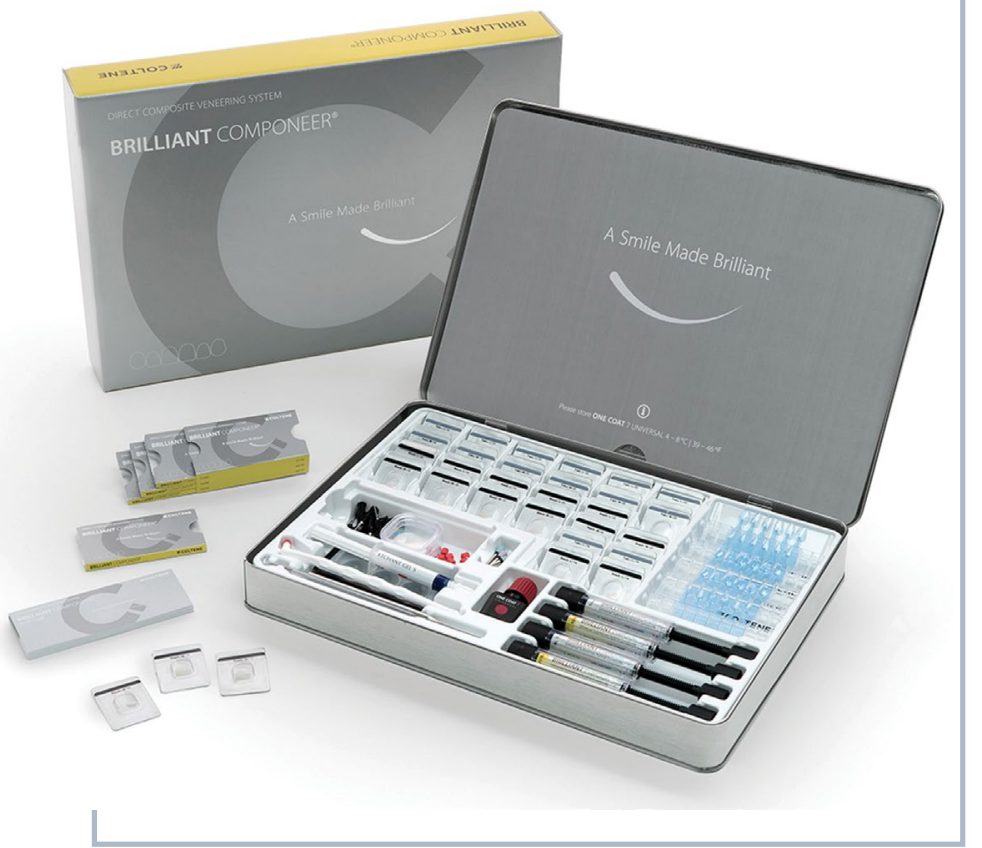

\section{Enduring treatment needs a foundation of oral health}

Empowered patients are choosing elective dental treatment to improve their health and wellbeing.

For successful clinical outcomes, effective daily cleaning will keep the result beautifully maintained, so recommend a regular routine using high-quality products.

Premium oral health brand TANDEX has brushes and interdental brushes, with clear packaging to help them find the right size for each space.

Packs show a PHD (passage hole diameter) and ISO number, which together form a unique combination, identified by the colour of the brush handle.

Support your patients to find the best tools and establish excellent behaviours for life, with TANDEX.

For more information on Tandex's range of products, visit https://tandex.dk/.

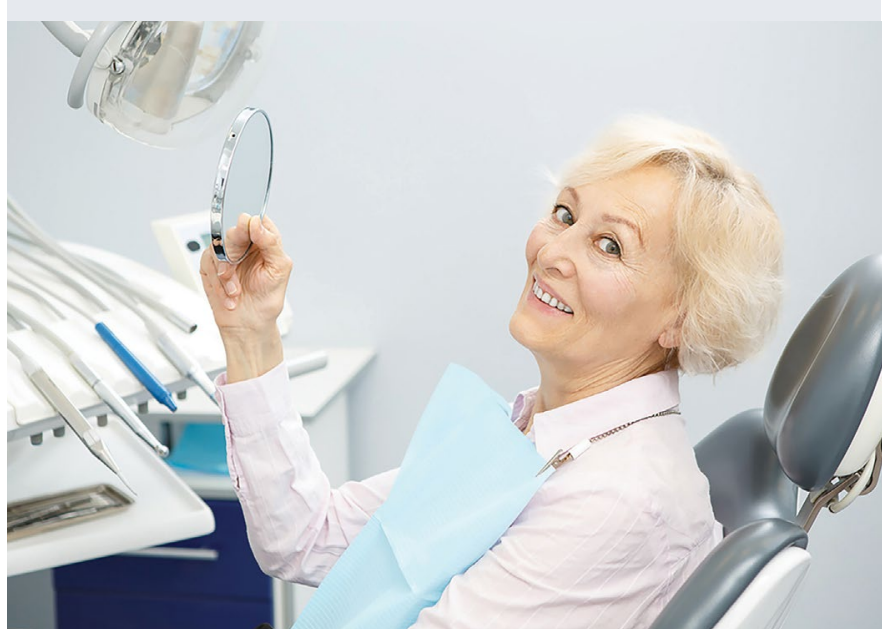

\section{Bringing full-arch rehabilitation within reach}

Many patients seek the advantages that full-arch immediate implant treatment can afford. NeoArch from Neodent is bringing these benefits within the reach of more people.

The highly flexible, predictable and affordable solution enables a simplified professional workflow that can be successfully adapted to various clinical indications. Optimised for immediate fixed treatment protocols, Neodent NeoArch delivers natural-looking aesthetics and restores function for high patient satisfaction.

The Neodent Helix GM implant is used with the concept, which is designed to ensure high primary stability and facilitate osseointegration in all bone types. ${ }^{1}$ Plus, as a Straumann Group brand, you and your patients can have complete confidence in the quality of the products and the support available whenever you need it.

Bring full-arch rehabilitation within the reach of more patients with Neodent NeoArch..

For more information, visit https://www.neodent-uk.co.

\section{Reference}

1. Steigenga J, Al-Shammari K, Misch C, Nociti F H Jr, Wang H L. Effects of implant thread geometry on percentage of osseointegration and resistance to reverse torque in the tibia of rabbits. J Periodontol 2004; 75: 1233-1241. 